ANTONIO, Andrea Tochio de. O psicólogo com o bisturi na mão: um estudo antropológico da cirurgia plástica. São Paulo: Annablume/ Fapesp, 2012. 190 p.

\title{
Rosamaria Carneiro
}

Universidade de Brasília E-mail:rosagiatti@yahoo.com.br

\section{Taniele Rui}

a tensão teórica e prática entre o que seria "reparador" ou "estéti-
co" nas cirurgias plásticas, a antropóloga Andrea Tochio opta pelo $^{\prime}$ que relaciona ambos os termos e não pelo que os corta, permitindo, desse modo, que se possa acompanhá-la numa etnografia artesanal dos meandros dos corredores, salas de consultas e "aberturas de pastas" do setor de cirurgia plástica do Hospital das Clínicas da Unicamp, uma das áreas médico-hospitalares mais importantes do país.

A obra ora publicada (originalmente dissertação de mestrado em antropologia, defendida em 2008) traz à tona arranjos, desarranjos e outras costuras existentes entre cirurgia plástica, classe social, gênero, envelhecimento e curso da vida, sistema público e sistema privado de saúde, bem como relações entre médicos situados na posição de professores e alunos (os residentes) e entre ambos e os "pacientes" que não estão doentes.

Nesse sentido, a investigação se insere, portanto, em uma fresta sui generis da antropologia da saúde: naquela em que a intervenção médica "pode esperar", ser solicitada e negociada pelo paciente e, que, assim, aparece intimamente conectada a uma "cultura psi" ou, 
utilizando os termos foucaultianos, a uma "cultura de si", de que para estar bem é preciso, antes, estar satisfeito com o próprio corpo, ou ainda, a uma "arte da existência" dominada pelo princípio segundo o qual é preciso, por diversos meios e técnicas, "ter cuidados consigo". (Foucault, 2009, 1985)

Pede-se atenção pelo fato de ser este um estudo sobre a cirurgia plástica nas classes populares e realizada no/pelo Sistema Único de Saúde, primeiro, porque, apressadamente se espera que tais cirurgias ocorram entre as camadas mais abastadas de modo particular e, em segundo lugar, por se pensar que em tais hospitais, onde os recursos são escassos, prevalecessem cirurgias de "reparação".

Suspendendo tais pressupostos, a autora se orienta por outras questões: como, num hospital público, se tomam decisões? Como essas decisões dialogam com a demanda da clientela que recorre ao serviço? Como demandas de ordem estética repercutem num hospital que deveria tratar de doenças? Além disso, ela escapa de um já saturado enfoque de discussão das cirurgias plásticas no Brasil e não se orienta por números e estatísticas, nem por interpretações consolidadas sobre a "ditadura da beleza, do corpo e da magreza" que afeta, sobretudo, a vida de mulheres. Atenta ao que há de melhor na produção contemporânea em torno dos marcadores sociais da diferença, Tochio (2012) aborda a temática pelo viés antropológico, de maneira detida e conforme o cotidiano desse hospital e as tramas tecidas em seu interior. Ao fazê-lo, oferece uma densa descrição de relações, de técnicas e de quereres.

Destaca-se o fato de que tal abordagem não é feita de maneira meramente desconstrutiva ou oposicionista. É no próprio correr da descrição que se nota que, de um lado, as classes menos privilegiadas da população anseiam por cirurgias estéticas e, de outro, que o "estético" tem, sim, espaço no SUS. De maneira talvez surpreendente, é possível observar que isso ocorre menos para a satisfação dos desejos dos pacientes e mais porque atende, antes ou também, aos interesses da própria instituição hospitalar, que é um hospital-escola, e, desse modo, daqueles que ali aprendem o ofício médico, os residentes, em processo de aprendizado. Portanto, quanto mais operam, mais se aper- 
feiçoam como cirurgiões. Observa-se, então, que interesses e escolhas são acionados e justificados de modo escalonado e em ordem crescente, conforme a equação ano de residência (R1, R2, R3...) e complexidade da plástica, o que em situações concretas se revela desde a otoplastia, com analgesia local, levada a cabo por um Rl até a abdominoplastia, com anestesia geral, feita por um R3. A tensão, assim, se dá entre prioridade de atendimento, escassez de recurso, demanda dos pacientes e necessidade de aprendizado.

O estudo em tela trata-se, portanto, de uma fértil etnografia que tematiza, principalmente, a interação prática e discursiva entre médicos e pacientes, por meio da manipulação de corpos através de uma técnica específica de sua produção: a cirurgia plástica. Isso posto, e logo passando aos comentários mais detidos sobre o conteúdo do livro, recomenda-se a obra aos leitores interessados no vasto campo da antropologia da saúde, das relações de gênero e com recorte geracional; e igualmente a indica-se aos interessados no desvelamento da prática médica e de seu aprendizado no cotidiano de um hospital-escola.

O livro, composto de seis capítulos, é complementado por introdução, considerações finais e prefácio escrito por Guita Debert, orientadora da pesquisa.

No primeiro capítulo, Andrea Tochio relata sua entrada em campo e algumas das vicissitudes desse processo, abordando os dilemas de uma pesquisa antropológica em espaços de saúde, a necessidade de tradução entre saberes nessa aventura fronteiriça e a importância do "jaleco branco" como sinalizador de legitimidade (ainda que, nesse aspecto, deixe o leitor sedento por uma reflexão mais detida em torno da implicação do uso da vestimenta no trato com os pacientes).

Descrever dificuldades de inserção em nossos universos de pesquisa, além de já consistir em própria investigação, figura em última instância como possibilidade de partilha de impressões e percalços metodológicos e, assim, material valioso para reflexões sobre ética em pesquisa, principalmente no campo das ciências humanas em saúde depois da edição da Portaria n. 196/96 do Ministério da Saúde/Conselho Nacional de Ética em Pesquisa. Chama a atenção, nesse sentido, a completa ausência de menção aos supostamente protetivos consenti- 
mentos informados, o que não implica, contudo, a falta de negociação entre pesquisadora e sujeitos de estudo, mas justamente o contrário, isto é, que o respeito às histórias observadas e às identidades pessoais passam por ajustes delicados e por acordos cotidianos que superam significativamente a simples anuência formal.

Em seguida (capítulo 2), Tochio descreve os "pacientes" atendidos no serviço, ressaltando a heterogeneidade de trajetórias e demandas. Junto a um público tão diverso faz-se notar que as justificativas imediatas para o desejo da cirurgia decorreram de sensações como "vergonha", "trauma", "complexo", "zombarias" e "aumento da autoestima". Justificativas que, ao longo do livro, serão examinadas em toda sua potencialidade, mas também em seus limites. Dessa maneira, se o objetivo do trabalho era mapear relações entre classe social, tipo de cirurgia e justificativa para tais intervenções, Tochio chega à conclusão de que a realidade do HC não foge muito à regra do que a Sociedade Brasileira de Cirurgia Plástica (SBCP) havia mapeado quanto às práticas nacionais.

Feita tal apresentação, passa-se, no capítulo seguinte (3), à descrição das práticas médicas, do encontro entre "pacientes" e cirurgiões plásticos, das estratégias e da burocracia caracterizadora das instituições sociais modernas. Da observação das consultas, nota-se que a oposição entre cirurgia estética e reparadora é um elemento importante na tomada de decisões. Se algumas cirurgias são, com certeza, reparadoras (tumor de pele, neurofibroma, cirurgia crânio-facial, fratura) é de modo mais complicado e no cotidiano do atendimento que cabe ao cirurgião definir quais os tipos de cirurgias estéticas podem ser consideradas reparadoras. Abre-se, assim, para um interessantíssimo jogo retórico, no qual os pacientes estão completamente inseridos, elaborado a fim de levar a cabo a cirurgia, ou não.

Longe de se restringir apenas a esse cenário, tal tensão, inclusive, já rondou as discussões em torno da mudança da nomenclatura da Sociedade Brasileira de Cirurgia Plástica, que chegou a ser nomeada de Sociedade Brasileira de Cirurgia Plástica Estética e Reconstrutora, em 1992, e voltou a ter o primeiro nome com a constatação de que, independente de ser estética ou reparadora, "é tudo cirurgia plástica". 
No entanto, essa que já se sabe ser uma falsa dicotomia ganha conotações dramáticas quando recursos econômicos e interesses divergentes entram em ação. Dessa forma, é possível se ver diante de um jogo de estratégias para conseguir e para negar a cirurgia pleiteada, que, certamente, configura um dos pontos mais fortes do livro. Os interesses são múltiplos e estão muito longe de serem uníssonos. Os médicos querem aprender e precisam praticar, mas quando não anseiam realizar o procedimento lançam mão de uma gama de subterfúgios, como postergar ou pedir ao paciente que lute pelo procedimento. Já os pacientes, que não são doentes, recorrem à retórica da reparação, buscam resultado rápido e despontam balizados pelo discurso do "cuidar-se para ser feliz", afastando a beleza da vaidade ou da futilidade.

No capítulo 4, a autora se envereda pelas noções de corpo e de projetos corporais para dar mais densidade à análise. Tomando de partida a presença de uma discursividade individualista de pessoa, Dumont menciona o estatuto do indivíduo como valor supremo e, assim, sobre a sua autonomização em relação ao corpo. Tal como ela mostra, a cirurgia como técnica adequaria o corpo à noção de pessoa e operaria a partir de uma concepção de corpos como matérias flexíveis e orientadas às expectativas pessoais, o que permite compreender as cirurgias como projetos, a um só tempo, pessoais e corporais. Para pensar sobre tais inflexões, a teoria de Thomas Csordas, de corpo como agente e produtor de cultura e não mais como substrato de significados, parece ser a grande parceira de Tochio. E, num escopo teórico ainda mais amplo, se a produção etnológica há tempos avisa que a produção de corpos implica na produção de pessoas, observa-se, a partir dessa descrição, que o mesmo se passa bem aqui, nos hospitais universitários.

Chega-se, assim e com força, ao quinto capítulo, em que a autora nos revela a origem do título da obra: uma frase proferida por um dos cirurgiões plásticos mais renomados do país (Ivo Pitanguy) em uma conferência sobre plásticas no Brasil - o que a leva também a refletir sobre a etiologia das "doenças" ou das razões que fazem um paciente escolher por uma plástica. O leitor se depara então com "a falta de autoestima como doença" e com o médico como "o psicólogo com o bisturi na mão". 
As justificativas, sobretudo dos pacientes, que acionam os elementos de uma "cultura psi" são retomadas, dessa vez como um imperativo moral. A "doença" psi se incumbe, nesses espaços ambulatoriais, de atenuar a relação entre cirurgia estética, vaidade e elitismo. Nessa esteira, caberia ao médico "fazer o paciente feliz", muito mais do que medicá-lo ou operá-lo. Ou seja, no limite, a infelicidade com o corpo funciona como patologia que deve ser resolvida mediante a construção do corpo desejado, aquele projetado ou idealizado pelo paciente a partir dos ditames sociais de belo/feio. E o sumamente interessante é que a cirurgia aflora como procedimento que pode curar desde a "falta de autoestima" até a depressão.

Diante disso, a antropóloga sinaliza a dificuldade do exercício da medicina nessas situações, pois o médico precisa, segundo eles próprios, discernir abalos psicológicos prévios, instabilidade emocional e capacidade individual de sofrer uma cirurgia plástica. E, desse modo, atuar como um psicólogo, terapeuta e analista, práticas que fogem ao seu processo de formação. Nessas vicissitudes, desponta a categoria "somatização" como tentativa de explicação para a doença que está antes na cabeça do que no corpo, na necessidade de uma reparação pontual ou estética que, ironicamente, repõe um dualismo corpo e mente.

No último capítulo da obra, a trama tecida ao longo de todas as páginas ao redor da díade estética/reparação vai se desvelando. Na verdade, a essa altura, já está claro que essa separação é muito tênue, longe de ser rígida e, no fundo, negociada em consultas e a partir de variados jogos de interesses. Em última instância, a ideia de que "toda cirurgia estética é reparadora e toda cirurgia reparadora é estética" aparece como síntese que possibilita explicar/ressignificar/recusar ou aceitar praticamente todos os casos.

Todavia, questões de gênero e geração pesam sobremaneira nessa conjunção, na medida em que, por exemplo, os casos de ginecomastias (realizada em homens com mamas grandes) foram todos considerados "reparadores". Na leitura da autora, tais cirurgias seriam enquadradas como reparadoras, em razão de se partir do pressuposto de que homens "naturalmente" não têm seios e aquilo seria uma 
desordem a ser "consertada", "porque seio é coisa de mulher" (Tochio, 2012, p.151). A separação reparação/estética, contudo, pode não ser tão simples ou ao menos mais confusa no caso das mulheres. A dor nas costas das mulheres que pleiteiam uma mamoplastia se confunde com o desejo de ter um seio mais bonito. O "incômodo" de ter pele sobrando na barriga depois de três gravidezes se mistura ao anseio de ter um abdômen aprazível. Isso posto, no entender da autora, uma série de construções sociais performativas dos sexos tendem a ser naturalizadas contribuindo para ditar o que seria estético e reparador, bem como para materializar diferenças que são históricas e culturais entre corpo masculino/feminino e estão pautadas pela premissa da heterossexualidade obrigatória.

Se gênero importa para esses corpos serem recortados e "rearranjados", o curso da vida também parece ser relevante. Mas, num outro sentido, a "natureza" que justifica a reparação de mamas em homens é a mesma que deve ser burlada com o passar dos anos. Nesse caso, o seu primado não é absoluto. Usando as palavras da antropóloga, "a cirurgia é uma tentativa de fugir das marcas do tempo, desnaturalizando processos tidos como naturais" (Tochio, 2012, p.159) - o que reproduz a ideia de "juventude como valor", tão criticada nos trabalhos de sua orientadora, Guita Debert. Com isso, a velhice desponta como uma espécie de "doença" que a plástica pode igualmente curar. O fator geração opera ainda como um localizador das partes do corpo e denota diferenças significativas. Por exemplo, entre as mulheres mais velhas, vale mais "operar" as partes visíveis (nariz, bocas, olhos), pois o corpo há muito já deixou de ser exposto.

Finalizando, diante dos dados apresentados, a antropóloga reforça e refina etnograficamente os argumentos de uma literatura que vem postulando que preservar a vida ou adequar-se aos modelos sociais é, por consequência, um dever moral que envolve uma "luta" que cada sujeito deve empreender para adquirir o corpo desejado/esperado. Nessas linhas, ela mostra que há vaidade e hedonismo, mas também demanda e introjeção por/de disciplina, principalmente dos mais pobres, atendidos no SUS e que precisam justificar a intervenção, de modo bem diferente daquele que paga e obtém o serviço. Nesse cenário, 
se o paciente é disciplinado, portador de um ethos puritano e faz por merecer, ele obtém a cirurgia; se, no entanto, tem um ethos hedonista, sua cirurgia é enquadrada como estética e nem sempre conquistada.

Em suma, ao perscrutar como a naturalização do dimorfismo sexual e da juventude são efetivadas em técnicas de cirurgia plástica, como o arranjo entre aprendizado e risco se relaciona a uma biopolítica, que adequa corpos a padrões sociais e como práticas discursivas são reproduzidas tanto pelos usuários como pelos médicos do sistema de saúde público, a autora contribui para desvelar o funcionamento de muitas de nossas categorias de pensamento, mas também para desestabilizá-las. Com o livro, nota-se que em torno da fronteira que liga e opõe estética e reparação estão envolvidos valores morais, pessoais, corporais e profissionais que disputam qual dano merece ser corrigido e quais os indivíduos que fazem jus ao procedimento.

\section{Referências}

FOUCAULT, Michel. História da sexualidade 3: o cuidado de si. Rio de Janeiro: Graal, 2009. (1985) 